\title{
Metabolic reprogramming and AMPK $\alpha 1$ pathway activation by caulerpin in colorectal cancer cells
}

\author{
HUA YU $^{1}$, HUIQIN ZHANG ${ }^{2}$, MINGJUN DONG ${ }^{1}$, ZHOU WU $^{1}$, ZHONGLEI SHEN ${ }^{1}$, \\ YANGYANG XIE ${ }^{1}$, ZHENFANG KONG $^{1}, \mathrm{XIAOYU}$ DAI $^{1^{*}}$ and BINBIN XU ${ }^{2 *}$ \\ ${ }^{1}$ Department of Anus and Intestine Surgery, ${ }^{2}$ Department of Nutriology, Ningbo No. 2 Hospital, \\ Ningbo, Zhejiang 315010, P.R. China
}

Received July 8, 2016; Accepted November 21, 2016

DOI: 10.3892/ijo.2016.3794

\begin{abstract}
Caulerpin, a secondary metabolite from the marine invasive green algae Caulerpa cylindracea is known to induce mitochondrial dysfunctions. In this study, the anticancer property of caulerpin was assessed in a panel of colorectal cancer cell lines. We demonstrated that caulerpin inhibited oxidative phosphorylation (OXPHOS) and facilitated an early intervention of the mitochondrial function, via inhibiting mitochondrial complex I, accompanied by the dissipation of mitochondrial membrane potential and a surge of reactive oxygen species (ROS) generation. Moreover, in response to the increment in AMP/ATP ratio, the energy sensor AMP-activated protein kinase (AMPK) was activated by caulerpin treatment in a calcium/calmodulin-dependent protein kinase 2 (CaMKK2)-dependent manner. Distinguished effect on glycolysis was observed at different time-points after caulerpin treatment. Glycolysis was enhanced after a short time treatment with caulerpin, associated with upregulation of glucose transporter 1 (GLUT1), hexokinase II (HKII) and
\end{abstract}

Correspondence to: Dr Xiaoyu Dai, Department of Anus and Intestine Surgery, Ningbo No. 2 Hospital, 41 Xibei Street, Ningbo, Zhejiang 315010, P.R. China

E-mail: daixiaoyupharmacy@163.com

Dr Binbin Xu, Department of Nutriology, Ningbo No. 2 Hospital, 41 Xibei Street, Ningbo, Zhejiang 315010, P.R. China

E-mail: xubbdrug@163.com

${ }^{*}$ Contributed equally

Abbreviations: CRC, colorectal cancer; OXPHOS, oxidative phosphorylation; ETC, electron transport chain; AMPK, AMP-activated protein kinase; CaMKK2, calcium/calmodulin-dependent protein kinase 2; GLUT1, glucose transporter 1; HKII, hexokinase II; PFKFB3, 6-phosphofructo-2-kinase; 2DG, 2-deoxy-D-glucose; 3BP, 3-bromopyruvate; MMP, mitochondrial membrane potential; ROS, reactive oxygen species; PBS, phosphate-buffered saline; OCR, oxygen consumption rate; ECAR, extracellular acidification rate; sgRNA, single guide RNA

Key words: colorectal cancer, caulerpin, OXPHOS, AMPK, glycolysis, mTORC1 6-phosphofructo-2-kinase (PFKFB3) protein expressions. However, long-term activation of AMPK by caulerpin damaged the glycolysis and glucose metabolism in colorectal cells, finally causing cell death. The persistent effect of caulerpin was mediated by AMPK $\alpha 1$, rather than AMPK $\alpha 2$, to abolish cell viability through hindering mTORC1-4E-BP1 axis. Moreover, caulerpin synergized with the glycolytic inhibitor $3 \mathrm{BP}$ in inhibiting cellular proliferation both in vitro and in vivo. Our findings on the previously uncharacterized anticancer effects of caulerpin may provide potential therapeutic approaches targeting the colorectal carcinoma metabolism.

\section{Introduction}

Colorectal cancer (CRC) is one of the most aggressive malignancies worldwide. Twenty percent of primary colorectal cancer diagnoses reveal remote metastases. Available therapies still offer a poor prognosis and patients have a $<10 \%$ five-year survival rate (1). As evidenced by genetic modifications, environmental impacts, diet and lifestyles, the underlying mechanisms of CRC have been intensively studied.

Dysregulation of cell energetics was just counted in as one of the cancer hallmarks. Most cancers have a high request for nutrients and energy to support their rapid growth. Almost a century ago, the Nobel laureate Otto Warburg discovered more lactate (indicating higher glycolysis) was secreted in cancer cells than normal cells under aerobic conditions (2). This finding was later termed as the 'Warburg effect', indicating the hypothesis that even equipped with normal mitochondria, cancer cells still relied on both mitochondrial oxidative phosphorylation (OXPHOS) and glycolysis to sustain survival and growth (3).

Mitochondria are important players in the maintenance of cellular homeostasis, as they generate ATP via OXPHOS. Mitochondrial metabolism occurs during the tricarboxylic acid (TCA) cycle. Electron transport chain (ETC) has, therefore, become a crucial focus of cancer treatment. In addition, TCA cycle provides intermediates for amino acid and lipid synthesis. The amplified demand for energy supplement in cancer cells endows targeting ETC a promising strategy to restrict cancer progression. Compounds that target the mitochondria have drawn worldwide attention. For example, metformin, a diabetes drug, obstructed mitochondrial 
complex I and exhibited impressing effects on various cancer models (4).

As a metabolic sensor in energy homeostasis, AMP-activated protein kinase (AMPK) is important for regulating mitochondrial content and maintaining glucose homeostasis. In metabolically active cancer cells, impaired mitochondrial OXPHOS would lead to AMPK activation. AMPK $\alpha$ can be phosphorylated by upstream kinases, including calcium/calmodulin-dependent protein kinase 2 (CaMKK2), liver kinase B1 and TAK1 (5). Reactive oxygen species (ROS)-dependent increases in cytosolic calcium activated AMPK signaling via CAMKK2 (6). One of the most important consequences of AMPK activation was mTORC1 inactivation. AMPK/mTOR activation has been demonstrated to be involved in mesenchymal stem cells promoted-colorectal cancer progression (7). Moreover, mTOR signaling was greatly provoked in glandular elements of CRC and colorectal adenomas with advanced intraepithelial neoplasia (8).

Other than inhibiting TCA, blunting aerobic glycolysis is also a promising approach to selectively inhibit cancer cells which mainly rely on this pathway. Enzymes involved in the glycolytic pathway served as substrates for anticancer therapy. Right-sided colon tumors showed significantly higher glucose transporter 1 (GLUT1) mRNA levels, which is a rate-limiting transporter for glucose uptake (8). Hexokinase II (HKII) catalyzes the ATP-dependent phosphorylation of glucose. High HKII and low p-pyruvate dehydrogenase expression in the invasive lesions of CRC tumors is predictive of tumor aggressiveness $(9,10)$. Recently, several potent glycolytic inhibitors have been developed, such as 2-deoxy-D-glucose (2DG) and 3 -bromopyruvate (3BP). 3BP is an inhibitor of HKII $(11,12)$.

The mitochondrial damage induced by caulerpin, a Caulerpa spp. algal pigment, was first mentioned by Liu et al (13), who suggested that mitochondrial respiration can be intervened by caulerpin via suppressing ETC complex I of breast cancer cells in hypoxia. Recently, the study group of Ferramosca et al found that caulerpin selectively repressed the activity of complex II in rat liver mitochondria (14). The observations that caulerpin suppresses HIF-1 activation and displays cytotoxicity to human dermal fibroblasts support further exploration into the anticancer mechanism of caulerpin. Recent studies showed that glycolysis inhibitors stimulated cell death and sensitized cancer cells to chemotherapeutic agents in various types of cancers $(15,16)$. To date, there is no published literature showing that glycolysis inhibitors sensitized colorectal cells to caulerpin.

Although caulerpin inhibited mitochondrial respiration, whether disturbing complex I would abolish cells proliferation remained obscure. Moreover, activation of the energy sensor AMPK can promote glycolysis to replenish the loss of ATP. Herein, our study aimed to explore the intracellular molecular mechanism involved in caulerpin-modulated energy metabolism in CRC cell lines and further examine whether the combination of caulerpin and glycolysis inhibitors will orchestrate the stimulation of cell death both in vitro and in vivo.

\section{Materials and methods}

Chemical and reagents. Caulerpin (Fig. 1A) of 99\% purity was purchased from Yuanye Pharmaceutics (Shanghai, China).
A stock solution of metformin was made at a concentration of $100 \mathrm{mM}$ in DMSO and stored at $-20^{\circ} \mathrm{C}$. KN93, 2DG and 3BP were obtained from Sigma (Shanghai, China). Antibodies against PARP, p-p70S6K, p70S6K, p-S6, S6, p-4EBP1, 4EBP1, AMPK $\alpha 1, \mathrm{AMPK} \alpha 2$ and $\beta$-actin were purchased from Santa Cruz Biotechnology, Inc. (Santa Cruz, CA, USA). AMPK $\alpha$, p-AMPK $\alpha$ (Thr172), p-ACC (Ser79), ACC, procaspase-7, procaspase-9 antibodies were purchased from Cell Signaling Technology (Denver, MA, USA). Horseradish peroxidase-labeled secondary antibodies were obtained from Promega (Madison, WI, USA).

Cell culture. The human colorectal cancer cell lines HCT116 and HT29 were obtained from ATCC. LOVO and SW480 were obtained from the Cell Bank of the Shanghai Institute of Biochemistry and Cell Biology, Shanghai, China (http://www. cellbank.org.cn). All cell lines were cultured in DMEM medium supplemented with $10 \%$ fetal bovine serum, $100 \mathrm{U} / \mathrm{ml}$ penicillin and $100 \mu \mathrm{g} / \mathrm{ml}$ streptomycin and maintained in a humidified atmosphere at $37^{\circ} \mathrm{C}$ with $5 \% \mathrm{CO}_{2}$. For glucose deprivation experiments, medium was replaced with DMEM containing non-glucose (Invitrogen, Carlsbad, CA, USA).

Cell viability assay. The effects of drug treatment on the viability of colorectal cell lines were assessed with a cell counting kit- 8 from Sigma (17), as described by the manufacturer. Briefly, $2 \times 10^{4}$ cells were seeded into 96 -well plates. After treatment, CCK-8 solution was added to each well and cells were further incubated at $37^{\circ} \mathrm{C}$ for $2 \mathrm{~h}$. The absorption was measured using a multiskan spectrum microplate reader at $450 \mathrm{~nm}$. All the experiments were repeated at least three times.

Apoptosis detection. Briefly, the cells were treated with caulerpin for $24 \mathrm{~h}$. Cells $\left(1 \times 10^{6}\right)$ were centrifuged and harvested (18). Next, the cells were suspended in binding buffer, containing Annexin V-FITC and PI and then incubated for $15 \mathrm{~min}$ in the dark at room temperature. The stained cells were analyzed using a FACSCanto flow cytometer (BD Biosciences, Flanklin Lakes, NJ, USA).

Mitochondrial membrane potential (MMP) and ROS determination. Briefly, LOVO and SW480 cells were seeded in a 12 -well plate at $\sim 80 \%$ confluence. After receiving indicated treatment, cells were washed twice with phosphate-buffered saline (PBS) and incubated at $37^{\circ} \mathrm{C}$ for $30 \mathrm{~min}$ in buffer solution containing lipophilic cation JC-1 (KeyGen, Nanjing, China) or DCFDA (Invitrogen), cells were re-suspended and fluorescence was measured using a FACSCalibur (BD Biosciences). Two fluorescence parameters, channel 1 (green fluorescence, FL1) at $530 \mathrm{~nm}$ and channel 2 (red fluorescence, FL2) at $590 \mathrm{~nm}$, were used to measure MMP (19). Bright green fluorescence produced by DCFDA means high level of ROS (20).

Western blot analysis. Cells following different treatments were lysed with RIPA buffer. Protein concentration was determined using a Coomassie blue staining method (21). An equal amount of protein $(50 \mu \mathrm{g})$ was separated on $10 \%$ SDS-PAGE and transferred to PVDF membranes. The membranes were incubated with primary antibodies in $5 \%$ BSA at $4^{\circ} \mathrm{C}$ 
overnight. The membranes were washed and incubated with HRP-conjugated secondary antibody for $1 \mathrm{~h}$ at room temperature. The immunoreactive bands were detected with an ECL kit (Beyotime Institute of Biotechnology, Shanghai, China).

Metabolic analysis. Rat liver mitochondria $(0.3 \mathrm{mg}$ protein $/ \mathrm{ml})$ and saponin-permeabilized or intact cells $\left(5 \times 10^{6}\right)$ were incubated with caulerpin for indicated time. The oxygen consumption rate (OCR) and extracellular acidification rate (ECAR) were measured using an XFe-96 Extracellular Flux Analyzer (Seahorse Bioscience, North Billerica, MA, USA). After attachment to XFe cell culture plates, cells were washed with XF assay medium and equilibrated for $1 \mathrm{~h}$. ECAR were determined by the supplement of 2DG. ATP content was examined from OCR differences from basal rate after adding oligomycin. Different substrates were added to evaluate mitochondrial respiration when respiratory complex I to IV was stimulated respectively. Bioenergetic profiling to distinguish the site within the ETC controlled by caulerpin was performed as previously described (22). Measurements were normalized by total protein content with Lowry assay.

Generation of AMPKal-knockoutcell lines with a CRISPR/Cas 9 system. Two single guide RNAs (sgRNA) targeting unique sequences of the AMPK $\alpha 1$ gene were designed and cloned into the pSpCas9 (BB)-2A-Puro (PX459) V2.0 (Plasmid \#62988; Addgene) plasmid, which contains a puromycin resistance cassette. sgRNAs were as follows: 5'-CACCGTACATTCTGG GTGACACGCT-3' and 5'-AAACAGCGTGTCACCCAGAAT GTAC-3'. After transfection, the cells were cultured in a medium containing puromycin for $48 \mathrm{~h}$ (23). Cells resistant to the drug were then selected by FACS for clonal expansion. Gene deficiency in LOVO cells was examined by western blotting with an anti-AMPK $\alpha 1$ antibody.

RNA interference. Scramble siRNA, siRNA targeting AMPK $\alpha 2$ and siRNA transfection reagent were purchased from Invitrogen (Carlsbad, CA, USA). Cells were transfected with Lipofectamine 2000 (Invitrogen) according to the instruction (24).

In vivo tumor growth assay. Four to 6-week-old athymic mice, which were obtained from SLAC Lab Animal Center of Shanghai (Shanghai, China), were housed under standard conditions. This experiment was conducted in accordance with the guidelines issued by the State Food and Drug Administration (SFDA of China). The experiments were approved by the Institutional Animal Care and Use Committee of Ningbo No. 2 Hospital, Ningbo, China. Cells $\left(1 \times 10^{7}\right)$ in culture medium were injected subcutaneously into the right flank of each mouse (25). Tumor size was monitored by using micrometer calipers every other day for a 30-days period and calculated with a formula: tumor volume $\left(\mathrm{mm}^{3}\right)=$ width $^{2} \mathrm{x}$ length $/ 2$. When tumor volume reached $\sim 75 \mathrm{~mm}^{3}$, nude mice were divided into three groups (6 mice/group): saline control, caulerpin $(30 \mathrm{mg} / \mathrm{kg}$, in saline with $0.2 \% \mathrm{CMC}-\mathrm{Na}), 3 \mathrm{BP}(15 \mathrm{mg} / \mathrm{kg}$, in saline) or combination group. The oral gavage was executed every other day. It began on day 1 , and finished on day 30 . At the end of the experiments, all the mice were euthanized. Tumor tissues were used for immunohistochemistry assay.
Immunohistochemistry. Paraffin-embedded sections were heat-fixed, deparaffinized, and rehydrated through a graded alcohol series (100, 95, 85 and 75\%). Antigen retrieval was performed with citrate buffer and treated with $3 \% \mathrm{H}_{2} \mathrm{O}_{2}$ to block endogenous peroxidase activity prior to the treatment with primary antibodies (anti-PCNA, 1:100; anti-mTOR, 1:200). The tissues were then incubated with the secondary biotinylated antispecies antibody. Counterstaining was performed using hematoxylin (26).

Statistical analysis. Data are expressed as means \pm SD. Statistical significance were performed using one-way ANOVA followed by unpaired Student's t-test. For comparison of multiple samples, the Tukey-Kramer test was used. All data were analyzed with GraphPad PRISM 5 (GraphPad Software, Inc., La Jolla, CA, USA).

\section{Results}

Caulerpin inhibits cell viability in colorectal cell lines. In the present study, we examined the anticancer property of caulerpin in various colorectal cancer cell lines (HT29, LOVO, HCT116 and SW480). A growth inhibitory effect was observed in the four colorectal cell lines after $48 \mathrm{~h}$ exposure, with $\mathrm{IC}_{50}$ values ranging from 20 to $31 \mu \mathrm{M}$ (Fig. 1B). Among them, LOVO cells were most sensitive, with $50 \%$ inhibition rate at the concentration of $20 \mu \mathrm{M}$, while SW480 cells were least sensitive to caulerpin. As shown in Fig. 1C, caulerpin induced apoptosis to colorectal cells, though to a different extent. Caulerpin augmented the activities of PARP-1, caspase- 9 and caspase-7 in LOVO cells, as indicated by their cleavage (Fig. 1D), but the broad-range caspase inhibitor z-VAD-fmk only partially prevented cell death, signifying that other caspase-independent signaling was engaged in the action of caulerpin (Fig. 1E).

Caulerpin inhibits OXPHOS and disturbs mitochondrial function via the inhibition of mitochondrial complex I. Previous findings illustrated that caulerpin impaired mitochondrial ETC in cisplatin-resistant C13 cells and human breast cancer T47D cells $(13,14)$, but its effects on oxygen consumption have not been fully addressed. Additionally, whether the emergence of an energy stress correlates with the anticancer activity of caulerpin in colorectal cells needs to be explored. In the present study, oxygen consumption was inhibited by $\sim 60 \%$ in SW480 and LOVO cells after caulerpin treatment. The phenomenon was more obvious in permeabilized cells than intact cells (Fig. 2A). LOVO cells pretreated with caulerpin (20 $\mu \mathrm{M}, 2 \mathrm{~h})$ were then permeabilized with saponin. Although malate and glutamate (ETC complex I substrates) failed to restore caulerpin-triggered downregulation of mitochondrial respiration in LOVO cells, complex II substrate succinate rescued mitochondrial respiration in LOVO cells pretreated with caulerpin, indicating that caulerpin caused impairment to complex I (Fig. 2B). The inhibitory effect of caulerpin on mitochondria respiration resembled that seen from rotenone, a complex I inhibitor (Fig. 2B). Moreover, in the incubation media containing succinate, respiration was suppressed by supplementation with complex III inhibitor antimycin A, proving that the ETC still works. A combination of TMPD/ascorbate (complex IV substrates) successfully rebooted respiration 

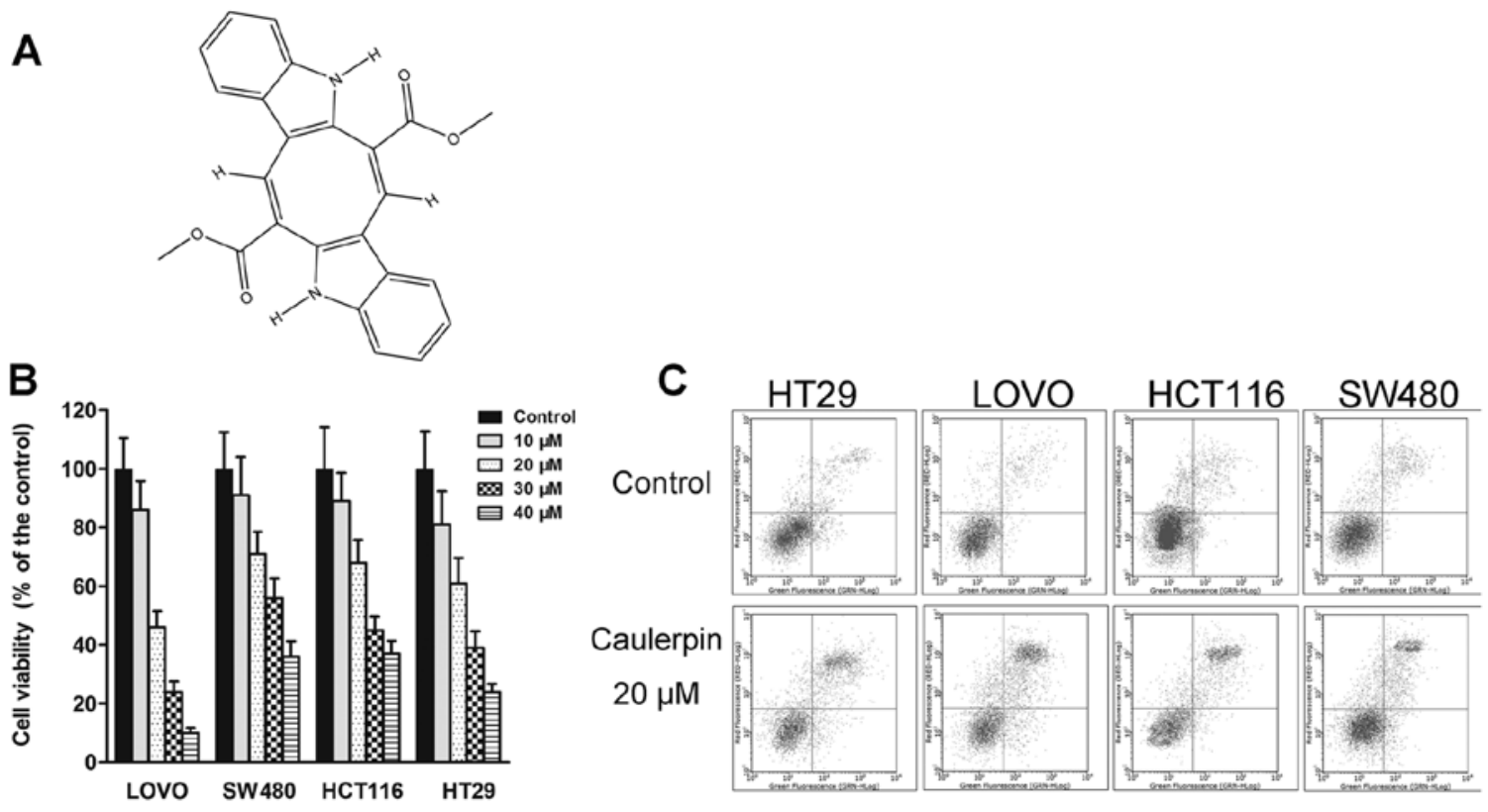

D

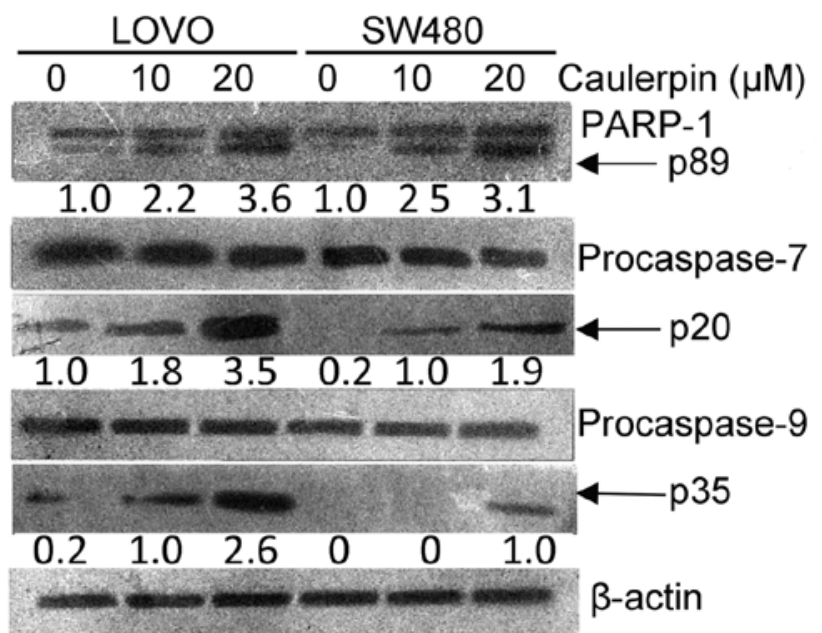

E

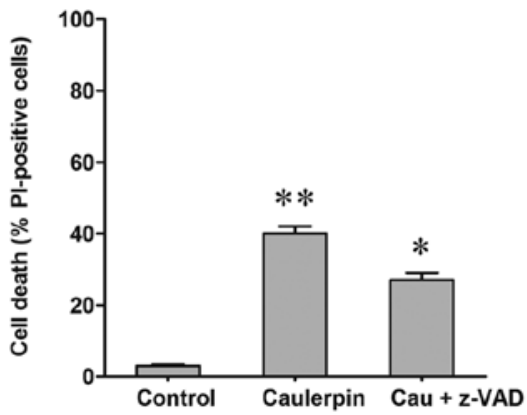

Figure 1. Effect of caulerpin on cell growth and apoptosis of CRC cell lines. (A) Structure of caulerpin. (B) Cells were exposed to various concentrations of caulerpin for $48 \mathrm{~h}$, and cell viability was assessed by the CCK-8 assay. (C) Annexin V-FITC/PI double-staining assay of the toxicity of caulerpin (20 $\mu \mathrm{M}$, $24 \mathrm{~h}$ ) was analyzed by flow cytometry in HT29, LOVO, HCT116 and SW480 cells. (D) Western blot assays were used to examine the expression of apoptosisrelated proteins after $24 \mathrm{~h}$ incubation with caulerpin: procaspase-9, procaspase-7 and PARP-1. (E) LOVO cells were co-treated with caulerpin (20 $\mu \mathrm{M})$ and the pan-caspase inhibitor $\mathrm{z}$-VAD-fmk $(50 \mu \mathrm{M})$ for $24 \mathrm{~h}$, and the cells were then subjected to flow cytometry to evaluate apoptosis. Mean $\pm \mathrm{SD}(\mathrm{n}=3)$. ${ }^{*} \mathrm{p}<0.05$ and ${ }^{* *} \mathrm{p}<0.01$ vs. control.

perturbed by antimycin A (Fig. 2C). In mitochondria isolated from rat liver, similar results were obtained. In the media containing malate and glutamate, oxygen consumption was suppressed due to caulerpin treatment, however, not in the presence of succinate (Fig. 2D). The results demonstrated that caulerpin brought about an intervention to mitochondrial function, via inhibition of mitochondrial complex I without interfering complexes II, III or IV.

Caulerpin induces a drop in mitochondrial membrane potential and a surge in ROS level. Since mitochondrial function was impaired by caulerpin, we then examined mitochondrial membrane potential $(\Delta \Psi \mathrm{M})$ and ROS with flow cytometry, repectively. JC-1 is a cationic dye which accumulates in mitochondria in response to potential change, and the rise in the green/red fluorescence intensity ratio reflects mitochondrial depolarization. Herein, JC-1 fluorescent probes were utilized to analyze $\Delta \Psi \mathrm{M}$. In Fig. 3B, a significant advance in green/red fluorescence ratio (almost 3-fold vs. control) was obtained in both LOVO and SW480 cells treated with caulerpin, pointing to a reduction in $\triangle \Psi \mathrm{M}$. FCCP, an electron transport chain uncoupler, was applied as the positive control. Likewise, intracellular ROS concentration was measured by flow cytometry with the fluorescence dye DCF-DA. In a concentration-dependent manner, caulerpin rapidly upregulated ROS level at $1 \mathrm{~h}$ post-induction, and up to $24 \mathrm{~h}$ (Fig. 3C).

Caulerpin stimulates AMPK signaling and inhibits mTORC1$4 E-B P 1$ axis. The metabolic profile of colorectal cancer cells was further examined with the Seahorse XF-e96 analyzer. 
A
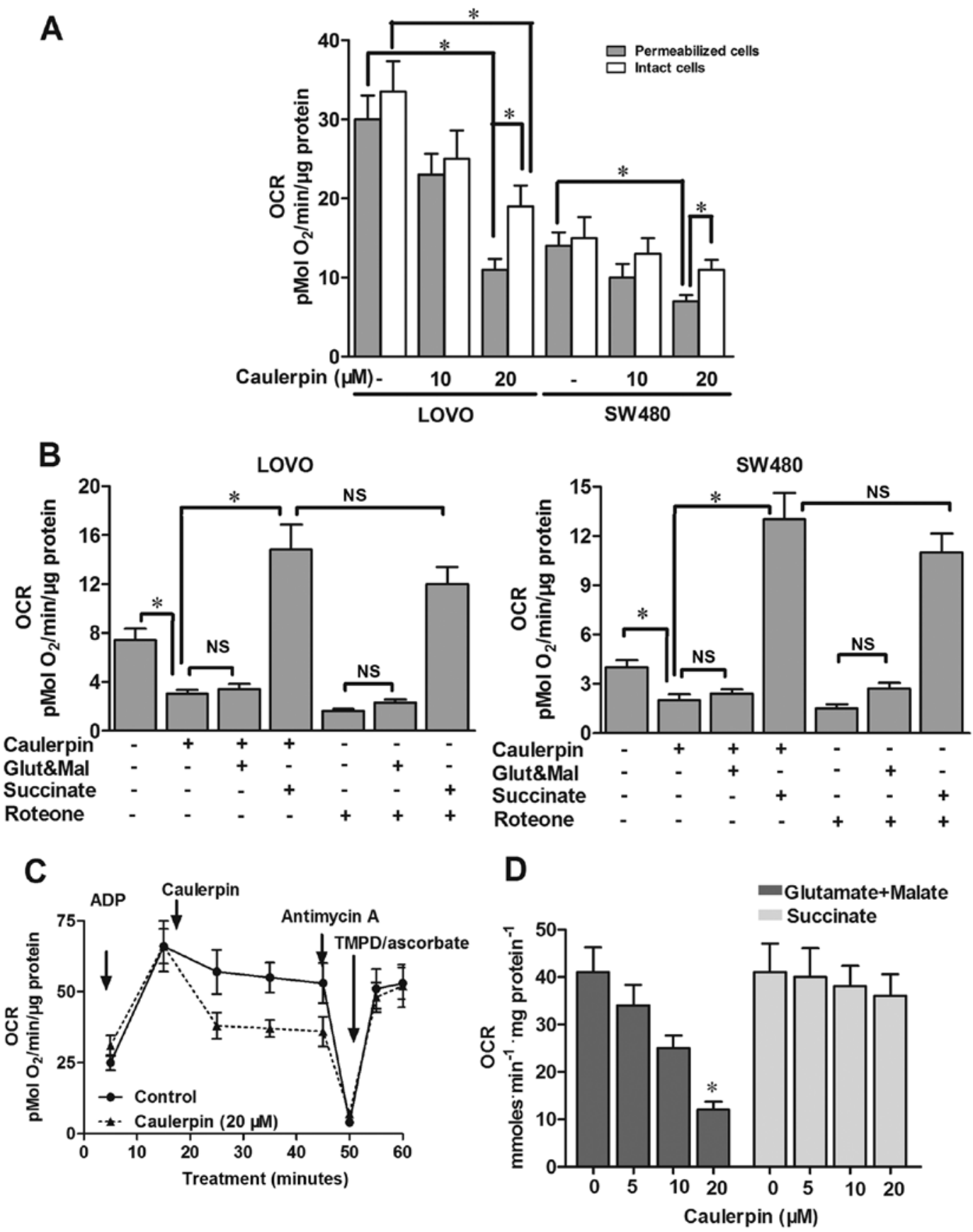

Figure 2. Caulerpin inhibits mitochondrial complex I function. After treated with caulerpin at $37^{\circ} \mathrm{C}$ for $2 \mathrm{~h}$, the metabolic profiles were evaluated with XF-e 96 analyzer. (A) OCR of intact and saponin-permeabilized LOVO and SW480 CRC cells. (B) Effect of complex I substrates (malate and glutamate) and complex II substrates (succinate) on OCR of LOVO and SW480 cells. (C) At $\mathrm{t}=5 \mathrm{~min}$ saponin-permeabilized LOVO cells were treated with $10 \mathrm{mM}$ ADP to trigger respiration. At $\mathrm{t}=15 \mathrm{~min}$ caulerpin $(20 \mu \mathrm{M})$ was added to cells. At $\mathrm{t}=40 \mathrm{~min}$ antimycin A was added. At $\mathrm{t}=45 \mathrm{~min}$ complex IV substrates TMPD/ascorbate was added to cells. (D) Oxygen consumption of mitochondria isolated from rat liver incubated with caulerpin and substrates of complex I or II. Mean \pm SD ( $\mathrm{n}=3$ ). " $\mathrm{p}<0.05$ as indicated.

Caulerpin treatment inhibited both maximal and basal respiration (Fig. 4A), accompanied by an increment in AMP/ATP ratio, which could be observed after $5 \mathrm{~min}$ and $1 \mathrm{~h}$ incubation with caulerpin in LOVO cells (Fig. 4B). AMPK is a crucial energetic sensor that is activated either by decreased cellular ATP levels or by ROS elevation (27). Activated AMPK will further suppress mTOR signaling for cellular adaptation in a stress condition (28). In the present study, caulerpin-triggered phosphorylation of AMPK and the phosphorylation of the downstream target ACC were observed in both cell lines, accompanied with inhibition of the downstream mTORC1 targets 4E-BP1 and S6 (Fig. 4C).

As a kinase responsive to oxidative activation upstream of AMPK, the essential role of CaMKII was explored to uncover the mechanism of caulerpin-elicited AMPK activation (29). As shown in Fig. 4D, the CaMKII inhibitor KN93 reduced caulerpin-induced ATP levels in colorectal cells, and induced a remarkable dephosphorylation of AMPK and ACC. These results signified that caulerpin-stimulated AMPK activation was CaMKII-dependent. 
A
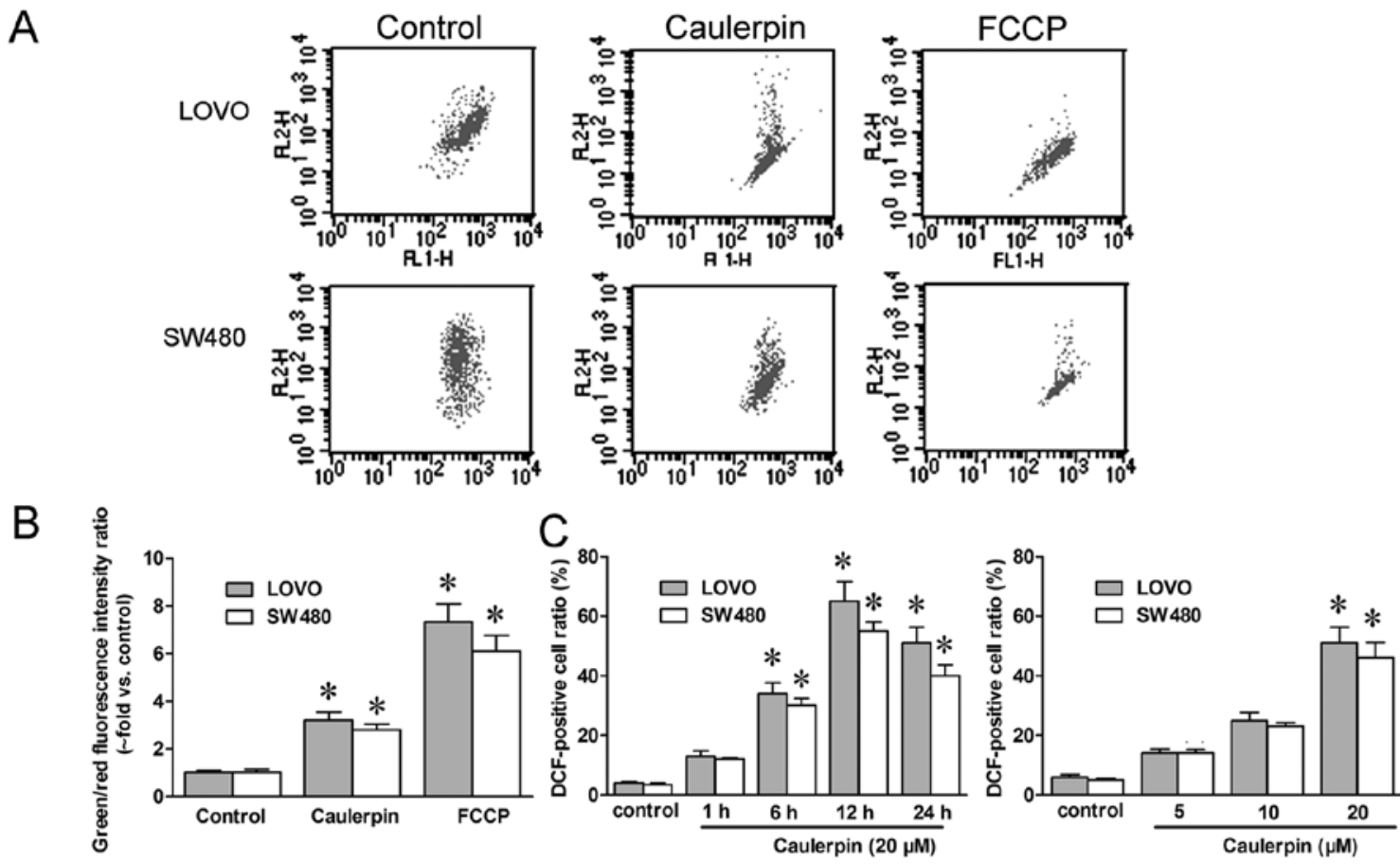

Figure 3. Caulerpin decreases $\triangle \Psi \mathrm{M}$ in LOVO and SW480 cells, and augments ROS. Cells were treated with caulerpin for $24 \mathrm{~h}$ and analyzed by flow cytometry. (A) The change of $\triangle \Psi M$ was determined using JC-1 staining. (B) The JC-1 ratio of green monomers/red aggregates vs. blank control is summarized. (C) ROS levels were measured by the DCFDA probe. The corresponding linear diagram of FACS is shown. Mean $\pm \mathrm{SD}(\mathrm{n}=3)$. ${ }^{\mathrm{p}}<0.05$ vs. control.

The role of $A M P K \alpha 1$ during caulerpin treatment. To further dissect the effect of AMPK isoforms on the viability of cells treated with caulerpin, the CRISPR-cas9 system was applied to knock out AMPK $\alpha 1$. crspAMPK $\alpha 1$ attenuated caulerpin-induced inactivation of mTOR pathway. Loss of AMPK $\alpha 1$ generated a compensatory growth in AMPK $\alpha 2$ expression (Fig. 5A). CCK-8 assay displayed that knock out of AMPK $\alpha 1$ protected cells against caulerpin-induced cytotoxicity ( 2 and $8 \mathrm{~h}$ ), while siAMPK $\alpha 2$ exhibited no significant influence on cell death, which was induced by caulerpin treatment (Fig. 5B).

Caulerpin exhibits different early and long-term effects on glycolysis. As a direct measure of ECAR, lactic acid was secreted by cells and thus serving as a hint for glycolytic activity. The baseline OCR/ECAR ratio was low in the SW480 cells and high in the LOVO cells, indicating a higher intrinsic glycolytic rate in SW480 cells than LOVO cells, which generate ATP primarily through OXPHOS (Fig. 6A).

We further examined whether caulerpin-triggered OXPHOS attenuation altered cell glucose metabolism. After $8 \mathrm{~h}$ treatment with caulerpin, glycolysis in LOVO cells was strengthened to compensate ATP loss, as revealed by significant increases in glucose uptake and lactate production (Fig. 6B and C). Moreover, upregulation of GLUT1, HKII, and 6-phosphofructo-2-kinase (PFKFB3) protein expression was also observed (Fig. 6D). Nevertheless, a prolonged exposure to caulerpin, unexpectedly, weakened glucose uptake in LOVO cells, as evidenced by downregulation of GLUT1 level after $48 \mathrm{~h}$ of caulerpin incubation (Fig. 6B and D). In the highly glycolytic SW480 cells, 8 h treatment with caulerpin exerted no significant effect on glucose metabolism; on the other hand, a remarkable decline of GLUT1 protein expression was observed after $24 \mathrm{~h}$ and continued after $48 \mathrm{~h}$. Therefore, in spite of the initial attempt to adapt to the energy stress, longterm incubation with caulerpin eventually elicited a notable impairment to glucose metabolism.

Synergistic effect of caulerpin combined with glycolysis inhibitors. To further characterize the biochemical events elicited by caulerpin and to examine its combination with the glycolytic inhibitor, we investigated nutrient signaling events and the AMPK kinase pathway. Glucose withdrawal promoted AMPK activation in both cell lines. Interestingly, levels of p-AMPK is higher in cells co-treated with caulerpin, 3BP $(25 \mu \mathrm{M})$ and glucose than cells treated with glucose only. These data emphasized the key role of the glycolytic switch for compensating ATP generation during caulerpin incubation (Fig. 7A). In Fig. 7B, in vitro $\mathrm{CCK}-8$ assays were applied to examine the cell viability. The $\mathrm{IC}_{50}$ of $3 \mathrm{BP}$ is $41.2 \pm 1.6$ and $38.9 \pm 1.6 \mu \mathrm{M}$ for LOVO and SW480 cells, respectively. As can be seen from the surviving factions, the viability of cells treated with 3BP $(25 \mu \mathrm{M})+$ caulerpin $(60 \mu \mathrm{M})$ was significantly lower than cells treated with 3BP or caulerpin alone. The combination index of 3BP $(25 \mu \mathrm{M})+$ caulerpin $(60 \mu \mathrm{M})$ is 0.67 for LOVO cells and 0.21 for SW480 cells, suggesting a synergistic effect. When $\mathrm{CI}$ is $>1$, it means antagonism. So we concluded that caulerpin plus 3BP may act synergistically in inhibiting cellular proliferation in vitro (Table I).

To further assess the antitumor efficiency of the combination in vivo, athymic nude mouse model bearing SW480 implanted xenografts were treated with control, 3BP, caulerpin, or a combination of both agents. Tumor growth was slower in caulerpin monotherapy group than the vehicle group. No significant difference was observed in tumor size between mice treated with saline and 3BP. However, the combination 
A
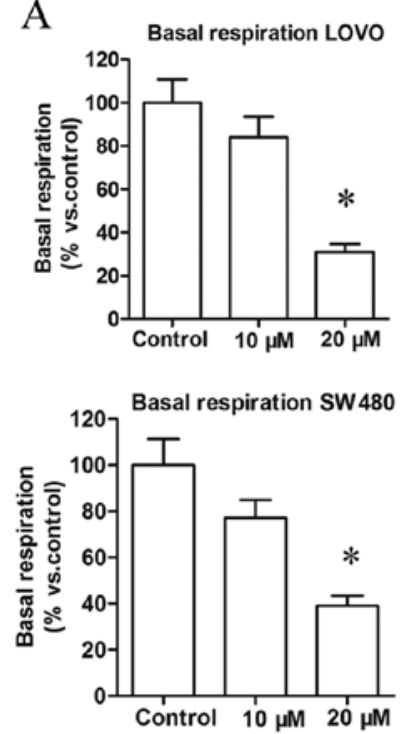
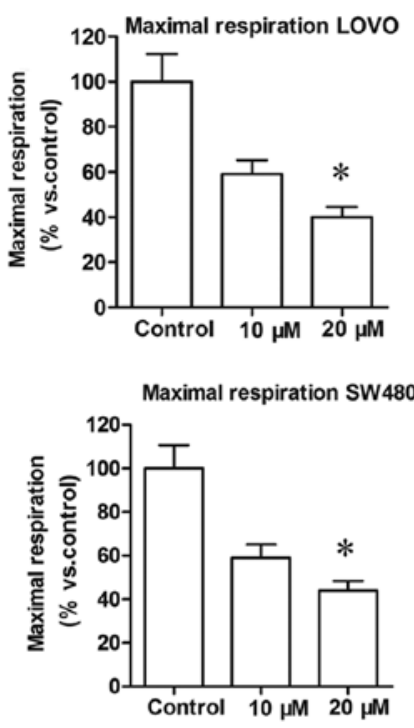

B
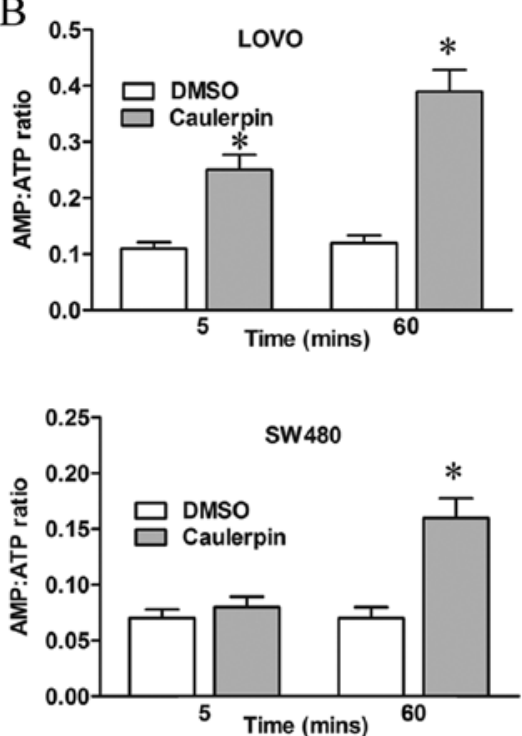

C LOVO

SW480
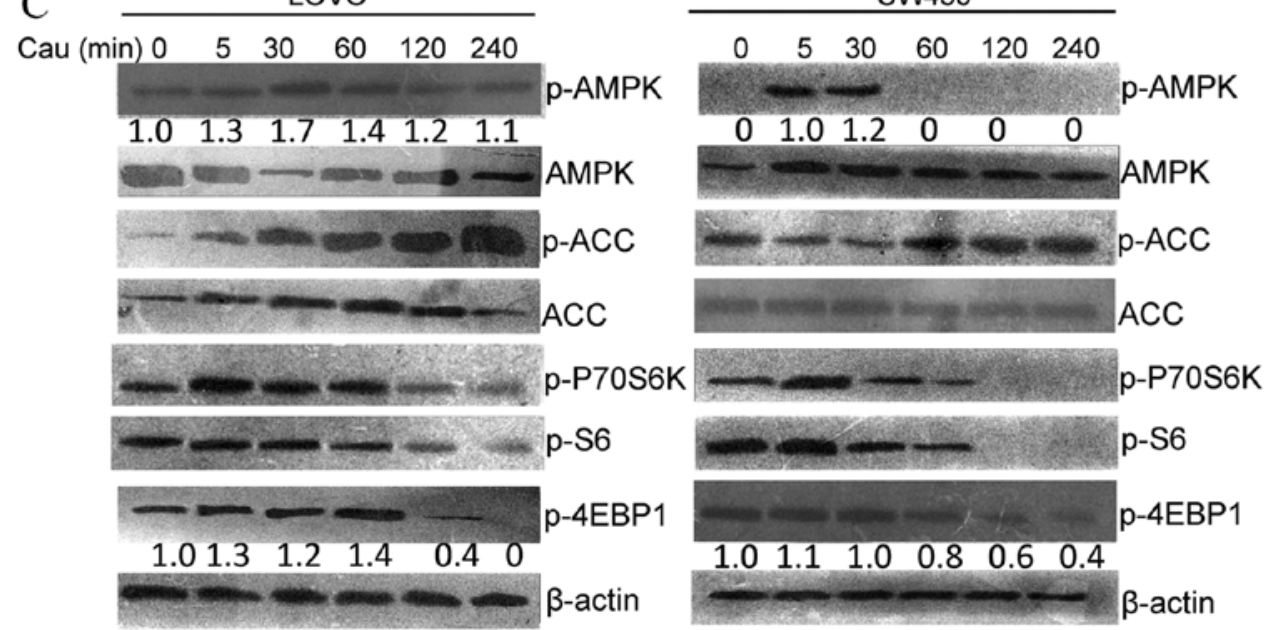

$\mathrm{D}$

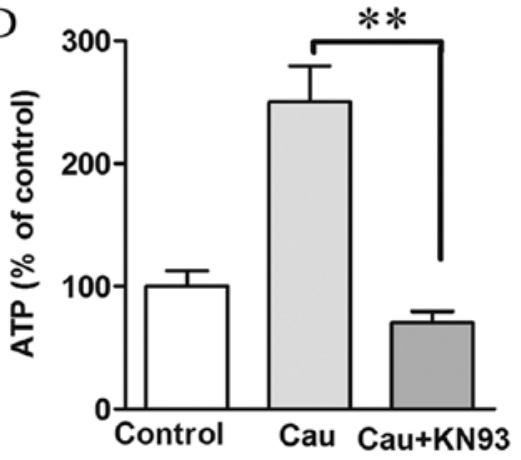

E

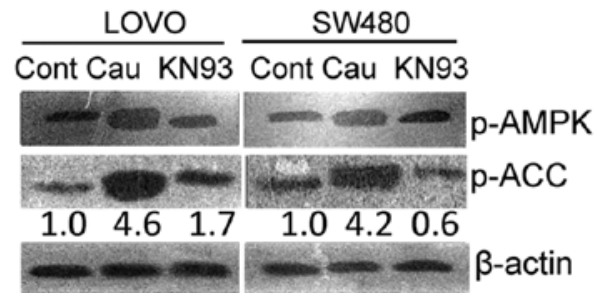

Figure 4. Caulerpin activates AMPK signaling and inhibits mTORC1-4E-BP1 axis. Cells were treated with caulerpin for $24 \mathrm{~h}$ and the Seahorse analyzer was applied to assess respiration and ATP levels. (A) Basal and maximal respiration and (B) AMP/ATP ratio in LOVO and SW480 cells. (C) Western blot assays were used to examine the expression of AMPK/mTORC1 signaling pathway after $4 \mathrm{~h}$ incubation with caulerpin. (D and E) After pretreated with KN93 (a CaMKII inhibitor, $5 \mu \mathrm{M}$ ) for $12 \mathrm{~h}$, LOVO cells were harvested followed by $2 \mathrm{~h}$ treatment with caulerpin $(20 \mu \mathrm{M})$. (D) ATP levels. (E) AMPK phosphorylation and activity (pACC was used as a surrogate) were examined by western blotting. Mean $\pm \mathrm{SD}(\mathrm{n}=3)$. ${ }^{*} \mathrm{p}<0.05$ vs. control.

of 3BP with caulerpin displayed remarkable tumor regression (Fig. 7C). Tumor xenograft sections were subjected to immunohistochemical analysis for p-mTOR and PCNA, which is an indicator for cell proliferation. PCNA and p-mTOR was significantly inhibited in combined treatment of 3BP with caulerpin (Fig. 7F).

\section{Discussion}

Cancer cell metabolism depends on a delicate balance between oxidative phosphorylation and glycolysis. The former keeps active to sustain energy needs required by the tumor, while the latter extensively enlarged to afford the needs of an invasive and 
A

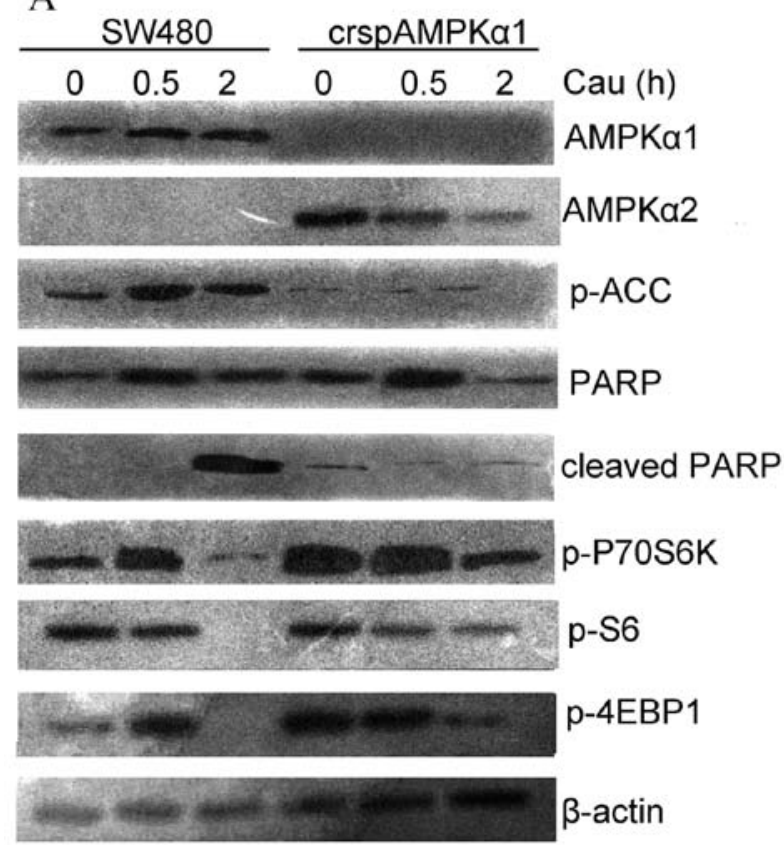

B

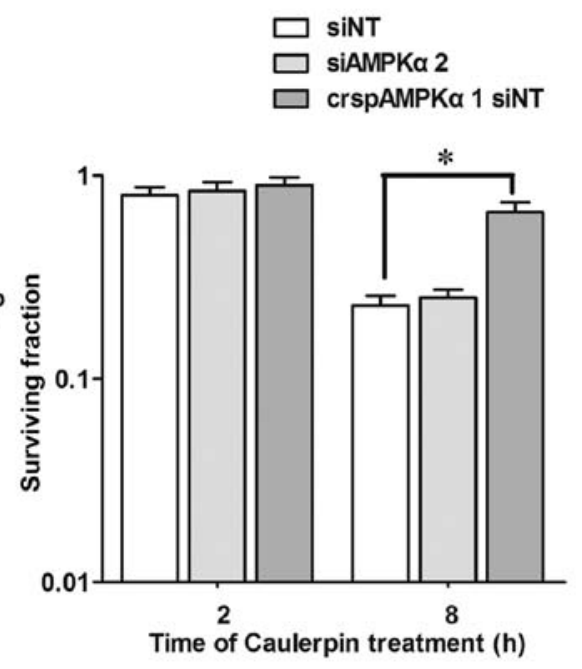

Figure 5. The divergent role of AMPK isoforms in the growth inhibiting effect of caulerpin. (A) Western blotting for AMPK-related protein expression of AMPK $\alpha 1$ knock out cells after caulerpin treatment $(20 \mu \mathrm{M})$. (B) Cells viability determined by CCK- 8 assay after 2 and $8 \mathrm{~h}$ caulerpin treatment $(20 \mu \mathrm{M})$. Mean $\pm \operatorname{SD}(\mathrm{n}=3) .{ }^{*} \mathrm{p}<0.05$ as indicated.

A

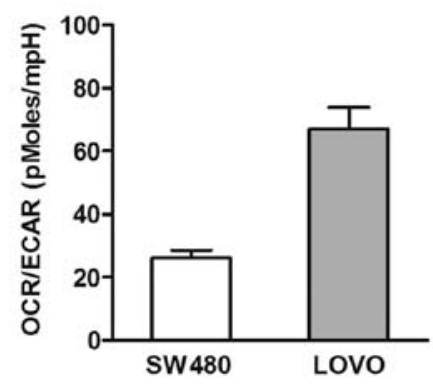

$\mathrm{D}$

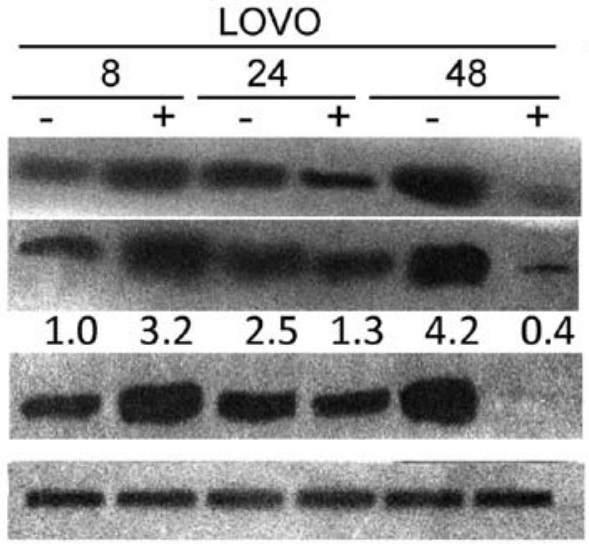

B

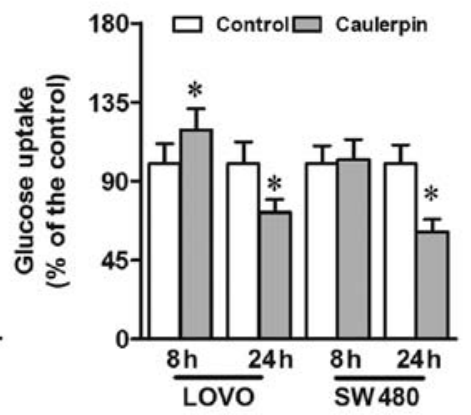

$\mathrm{C}$

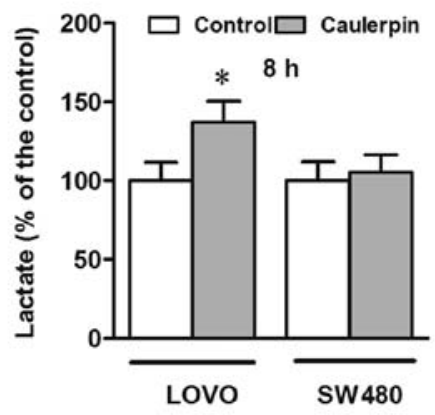

Figure 6. Caulerpin regulates glycolysis in CRC cells. (A) Baseline OCR/ECAR ratio in SW480 and LOVO cells. (B and C) Glucose uptake and lactate production of cells treated with caulerpin $(20 \mu \mathrm{M})$. (D) Western blot assays were used to examine glycolysis-related protein expression (GLUT1, HKII and PFKFB3) incubated with caulerpin $(20 \mu \mathrm{M})$ at the time points indicated. Mean $\pm \mathrm{SD}(\mathrm{n}=3)$. ${ }^{\mathrm{p}}<0.05$ vs. control.

rapid tumor growth (30). Recently, new therapeutic approaches that target multiple bioenergetics pathways have emerged.
Interference with this unique metabolic setting may provide novel opportunities for targeted anticancer therapy. 
A
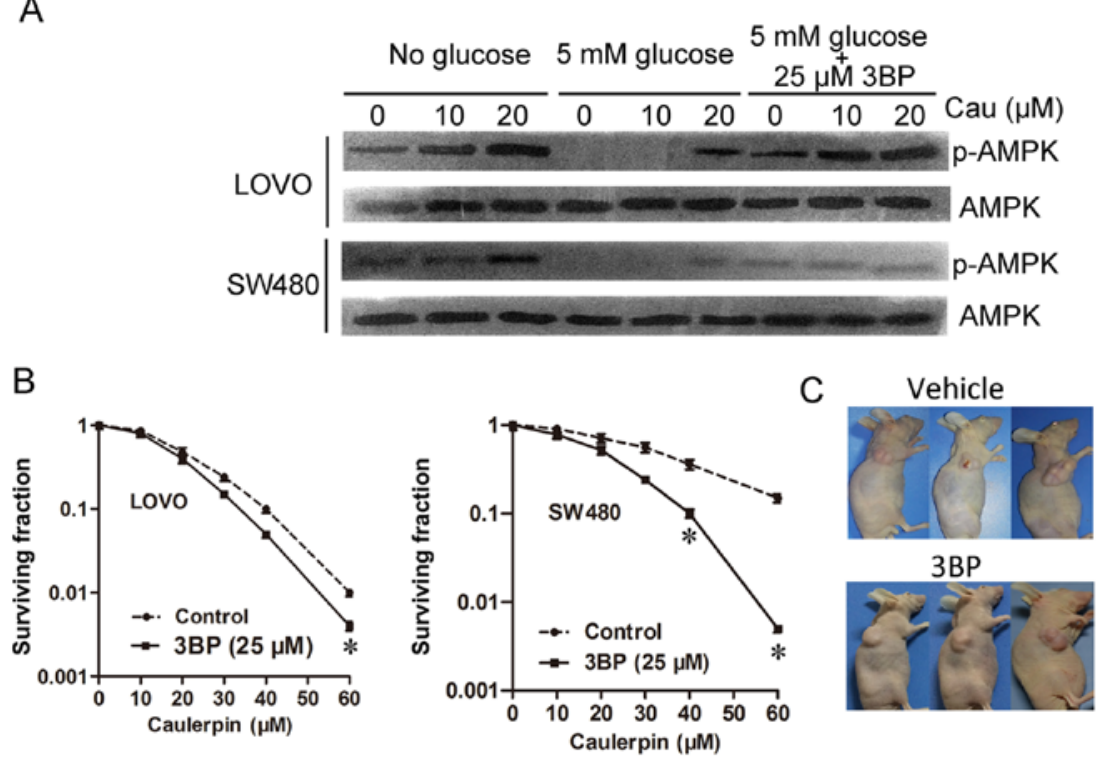

Combination
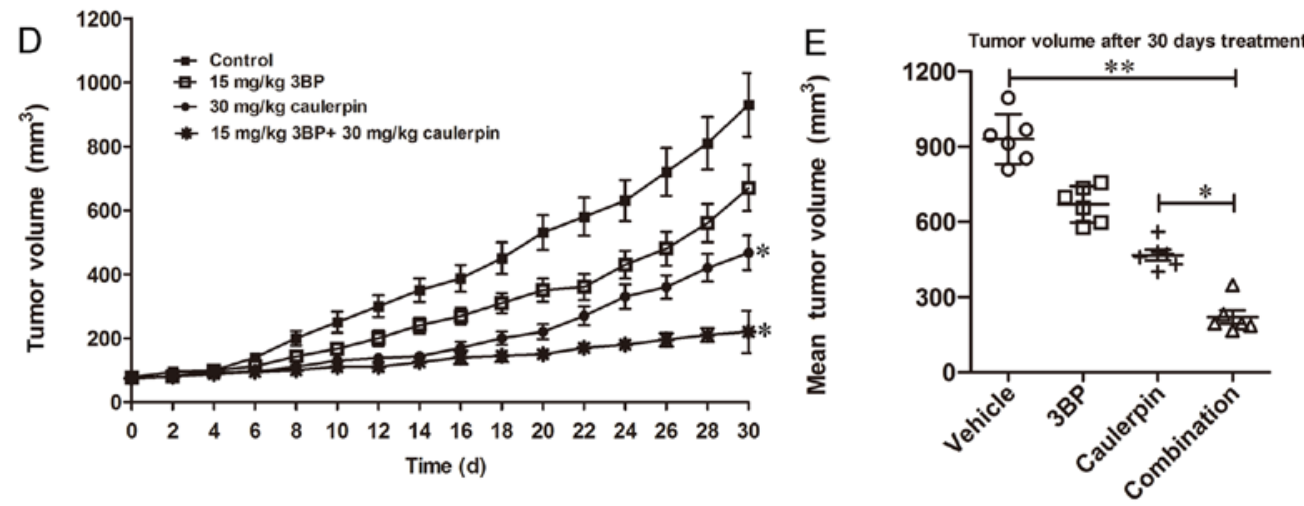

$\mathrm{F}$

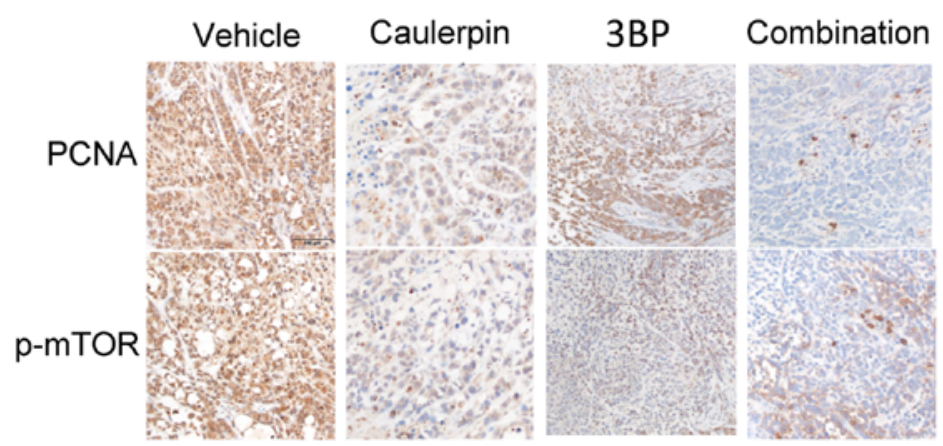

Figure 7. Synergistic effect of caulerpin combined with glycolysis inhibitors. (A) Effect of combination of caulerpin plus $3 \mathrm{BP}(25 \mu \mathrm{M})$ or glucose deprivation on AMPK activity. (B) Cell viability after co-treatment with caulerpin plus 3BP. (C) Representative xenografts of SW480 tumor images at the end of the treatment are shown. (D) Tumor volumes in SW480 xenografts were measured every other day using electronic vernier calipers. (E) Mean tumor volume (mm $\left.{ }^{3}\right)$ after 30-day treatment. (F) Representative images of PCNA and mTOR-immunostained tumor sections. Mean $\pm \mathrm{SD}(\mathrm{n}=6)$. ${ }^{*} \mathrm{p}<0.05$ vs. control or vehicle.

Table I. Calcusyn analysis reveals synergistic or antagonistic interactions between caulerpin and 3BP in CRC cells.

Combination index (CI)

\begin{tabular}{lccc}
\cline { 3 - 4 } Caulerpin $(\mu \mathrm{M})$ & 3BP $(\mu \mathrm{M})$ & LOVO & SW480 \\
\hline 20 & 25 & 1.43 & 1.38 \\
40 & 25 & 1.02 & 0.68 \\
60 & 25 & 0.67 & 0.21 \\
\hline
\end{tabular}

Here, we focused on the energy regulating effect of caulerpin, a mitochondrial ETC inhibitor. The obvious function included the inhibition of OXPHOS, the loss of MMP, and the rise of ROS in colorectal cancer cells. Although longtime treatment would finally drive cells to death, a cell reprogramming towards glycolysis largely attenuated the effect of caulerpin on cell death in the initial few hours after caulerpin treatment. Given that glycolysis triggered by caulerpin was a compensatory response, we reasoned that combination with glycolysis inhibitors may reinforce the anticancer effect of caulerpin. The marked increase in caulerpin-induced AMPK activation 
by the glycolysis inhibitor 3BP or by glucose deprivation evidently proves the above conclusion. The enhancement of caulerpin sensitivity by $3 \mathrm{BP}$ was also confirmed in the LOVO xenograft model, suggesting a key role of caulerpin in energy metabolism-based combinational therapies.

As a crucial metabolic organelle during carcinogenesis, mitochondria is regarded as a target for anticancer therapy (4). Mostly, cancer cells produce ATP via mitochondrial metabolism fueled by fatty acids and amino acids (31). Furthermore, mitochondrial oxidative metabolism is also required to sustain the redox balance. Specifically, ATP generation associated with ROS formation via complex I/III of the ETC (32). It is know that pro-tumorigenicity is a key characteristic of ROS. When the generation of ROS surpasses the intracellular clearance of ROS, cell-toxic oxidative stress will be stimulated. ETC complex I, constitutes the entry point of electrons and is an essential site for ROS generation (33). Caulerpin has been reported to reduce respiratory complex II activity and to exhibit cytotoxicity to human dermal fibroblasts (14). In this study, caulerpin considerably reduced oxygen consumption rate and ATP level in both SW480 and LOVO cells, accompanied by an elevation in ROS. Mitochondria isolated from rat liver have been selected as a system in which mechanisms of bioenergetics are not altered (14). Therefore, liver mitochondrial and LOVO cells were used to explore the complex interactions between caulerpin and the organelle. Studies showed that complex I inhibition by biguanides, such as phenformin and metformin, suppressed cancer development in vitro and in vivo $(34,35)$. However, the effective inhibiting concentrations of biguanides reached $\sim 50 \mathrm{mM}$, with the $\mathrm{IC}_{50}$ of caulerpin ranging from $20-31 \mu \mathrm{M}$. We found that in the media containing malate and glutamate (substrates of complex I), caulerpin treatment caused diminution of OCR, but similar results were not obtained in the presence of succinate (substrates of complex I), emphasizing the essential role of complex I in the inhibitory effect of caulerpin.

Dynamic changes in mitochondria are closely connected with post-translational modifications mediated by metabolic sensors, such as SIRT1 and AMPK (36). Among them, AMPK acts as a fuel-sensor that plays a vital role in manipulating bioenergetics metabolism in both normal and malignant cells (37). Under conditions of metabolic stress, activated AMPK will keep energy homeostasis by dampening energy consuming (anabolic) pathways and strengthening energy producing (catabolic) pathways to restore the loss of cellular ATP and de-energization (38). Caulerpin inhibited OXPHOS, accompanied by the decline of ATP content and concomitant activation of the energy sensor AMPK. Once activated, AMPK will promote glycolysis to replenish the loss of ATP. In this study, in both LOVO and SW480 cells, the level of p-AMPK was highest at 30 min after caulerpin treatment. We hypothesized that OXPHOS was significantly inhibited by caulerpin, and after $30 \mathrm{~min}$, glycolysis was activated to some content to counterbalance the loss of ATP. Therefore, the level of p-AMPK increased during the initial $30 \mathrm{~min}$ and decreased since $60 \mathrm{~min}$. AMPK activation by caulerpin was dependent on CAMKK2, an upstream effector of AMPK. In detail, AMPK $\alpha 1$ was demonstrated to mediate the function of caulerpin, since crspAMPK $\alpha 1$ protected cells against caulerpin-induced cytotoxicity and attenuated caulerpin-induced activation of mTOR pathway. But siAMPK $\alpha 2$ failed to exhibit impressive effect on cell death-induced by caulerpin treatment. Likewise, AMPK $\alpha 1$-shRNA has been proved to improve mTORC1 phosphorylation in colorectal cancer cells (39). Herein, we concluded that AMPK isoforms differentially regulated survival in response to caulerpin treatment.

Under energy stress, activated AMPK can further inhibit mTOR signaling for cellular adaptation in a stress condition (28). Several groups found that AMPK directly phosphorylated multiple components, such as TSC 2 in the mTORC1 pathway (40). Consistently, either AICAR (an AMPK activator) or glucose withdrawal greatly attenuated mTORC1 activity in TSC2-deficient cells (41). The p70S6K and eIF4E-binding proteins (4E-BPs), which can be phosphorylated by the mTOR complex, facilitate protein synthesis. The p70S6K regulates sterol synthesis and switches glucose metabolism from glycolysis to pentose phosphate pathway in cancer cells (42). In the present study, caulerpin triggered AMPK phosphorylation and further inhibited the mTORC1/4E-BP1 axis.

Heightened glycolysis is a major cancer hallmark. Firstly, we compared the basal metabolic profiles between LOVO and SW480 CRC cells. OCR/ECAR ratio of LOVO cells was significantly higher than that of SW480 cell, indicating that SW480 cells were highly glycolytic, while LOVO was a less glycolytic cell line which depended more on OXPHOS to produce ATP. This result could partially explain why $\mathrm{IC}_{50}$ in LOVO cells is lower than SW480 cells in response to caulerpin treatment, which was a potent inhibitor of mitochondrial respiration. Moreover, mRNA of Transketolase-like (TKTL)1, one of the key enzymes in glycolysis, was heterogeneously expressed, with high level in SW480 cells but very low level in LOVO cells $(43,44)$. HKII is a rate-limiting enzyme in glycolysis, thus giving rise to ATP decline and cell death. In colon cancer cells, knockdown of HKII suppressed proliferation, glycolysis, and lactate production under both normoxic and hypoxic conditions (45). In this study, distinguished effect was observed at different time-points after caulerpin treatment. Glycolysis was enhanced in the initial hours after treatment with caulerpin in LOVO cells rather than SW480 cells. However, long-term treatment of caulerpin considerably inactivated mTOR pathway, thus causing cell death in both LOVO and SW480 cells. GLUT1, HKII and PFKFB3 levels were weakened after $48 \mathrm{~h}$ of caulerpin incubation.

Recently, combined treatment targeting both glycolysis and mitochondria function emerges as an interesting alternative for cancer therapy. Mitochondrial ETC blockers have been reported to facilitate $2 \mathrm{DG}$-induced oxidative stress and cell killing effect in human colon carcinoma cells (46). In a phase I dose-escalation trial, the recommended dose of 2DG in combination with weekly docetaxel is $63 \mathrm{mg} / \mathrm{kg} /$ day with tolerable adverse effects (47). The most noteworthy side effects at this trial were reversible hyperglycemia, gastrointestinal bleeding and reversible grade 3 QTc prolongation (47). 3BP is a small-molecule pyruvate mimetic and anticancer drug, and its biological activity is attributed to alkylation of free thiol groups on the cysteine residues of proteins (48). 3BP directly inhibits mitochondrial bound HKII. The combination of caulerpin and 3BP retarded tumor growth in nude mice inoculated with SW480 cells, along with a decrement of PCNA and mTOR expression in IHC assays, showing the 
key role of AMPK/mTOR pathway in the anticancer activity of caulerpin.

The present study provided a preliminary insight into the potential use of caulerpin for the treatment of human colorectal cancer. Only transplanted nude mice model with xenografts was applied in our study to investigate the anticancer efficiency of caulerpin plus 3BP. Orthotopic CRC model can also be used in the future to verify the synergistical effect. In this study, we demonstrated that caulerpin disturbed the mitochondrial function mainly via inhibiting mTORC1-4E-BP1 axis. However, knocking out of AMPK $\alpha 1$ did not lead to a total abolishment of caulerpin-elicited cytotoxicity on LOVO cells. Moreover, the broad-range caspase inhibitor z-VAD-fmk only partially prevented cell death. Therefore, it is reasonable that other pathways are also involved in the actions by caulerpin in CRC cells. Thus, it is valuable to further uncover the interactions between AMPK signaling and other possible pathways in mediating the effects of caulerpin on colorectal carcinoma or other cancer models.

\section{Acknowledgements}

This study was supported by the Municipal key disciplines of Ningbo (no. 2013001) and the Natural Science Foundation of Ningbo (nos. 2014A610225 and 2016A610135).

\section{References}

1. Siegel R, Desantis C and Jemal A: Colorectal cancer statistics, 2014. CA Cancer J Clin 64: 104-117, 2014.

2. Warburg O, Wind F and Negelein E: The metabolism of tumors in the body. J Gen Physiol 8: 519-530, 1927.

3. Ward PS and Thompson CB: Metabolic reprogramming: A cancer hallmark even Warburg did not anticipate. Cancer Cell 21: 297-308, 2012

4. Wheaton WW, Weinberg SE, Hamanaka RB, Soberanes S, Sullivan LB, Anso E, Glasauer A, Dufour E, Mutlu GM, Budigner GS, et al: Metformin inhibits mitochondrial complex I of cancer cells to reduce tumorigenesis. eLife 3: e02242, 2014.

5. Inoki K, Kim J and Guan KL: AMPK and mTOR in cellular energy homeostasis and drug targets. Annu Rev Pharmacol Toxicol 52: 381-400, 2012.

6. Sinha RA, Singh BK, Zhou J, Wu Y, Farah BL, Ohba K, Lesmana R, Gooding J, Bay BH and Yen PM: Thyroid hormone induction of mitochondrial activity is coupled to mitophagy via ROS-AMPK-ULK1 signaling. Autophagy 11: 1341-1357, 2015.

7. Wu XB, Liu Y, Wang GH, Xu X, Cai Y, Wang HY, Li YQ, Meng HF, Dai F and Jin JD: Mesenchymal stem cells promote colorectal cancer progression through AMPK/mTOR-mediated NF- $\kappa B$ activation. Sci Rep 6: 21420, 2016.

8. Zhang YJ, Dai Q, Sun DF, Xiong H, Tian XQ, Gao FH, Xu MH, Chen GQ, Han ZG and Fang JY: mTOR signaling pathway is a target for the treatment of colorectal cancer. Ann Surg Oncol 16 2617-2628, 2009.

9. He X, Lin X, Cai M, Zheng X, Lian L, Fan D, Wu X, Lan P and Wang J: Overexpression of Hexokinase 1 as a poor prognosticator in human colorectal cancer. Tumour Biol 37: 3887-3895, 2016.

10. Hamabe A, Yamamoto H, Konno M, Uemura M, Nishimura J, Hata T, Takemasa I, Mizushima T, Nishida N, Kawamoto K, et al: Combined evaluation of hexokinase 2 and phosphorylated pyruvate dehydrogenase-E1 $\alpha$ in invasive front lesions of colorectal tumors predicts cancer metabolism and patient prognosis. Cancer Sci 105: 1100-1108, 2014.

11. Gandham SK, Talekar M, Singh A and Amiji MM: Inhibition of hexokinase-2 with targeted liposomal 3-bromopyruvate in an ovarian tumor spheroid model of aerobic glycolysis. Int $\mathbf{J}$ Nanomedicine 10: 4405-4423, 2015.

12. Xintaropoulou C, Ward C, Wise A, Marston H, Turnbull A and Langdon SP: A comparative analysis of inhibitors of the glycolysis pathway in breast and ovarian cancer cell line models. Oncotarget 6: 25677-25695, 2015.
13. Liu Y, Morgan JB, Coothankandaswamy V, Liu R, Jekabsons MB, Mahdi F, Nagle DG and Zhou YD: The Caulerpa pigment caulerpin inhibits HIF-1 activation and mitochondrial respiration. J Nat Prod 72: 2104-2109, 2009.

14. Ferramosca A, Conte A, Guerra F, Felline S, Rimoli MG, Mollo E, Zara V and Terlizzi A: Metabolites from invasive pests inhibit mitochondrial complex II: A potential strategy for the treatment of human ovarian carcinoma? Biochem Biophys Res Commun 473: 1133-1138, 2016.

15. Graham NA, Tahmasian M, Kohli B, Komisopoulou E, Zhu M, Vivanco I, Teitell MA, Wu H, Ribas A, Lo RS, et al: Glucose deprivation activates a metabolic and signaling amplification loop leading to cell death. Mol Syst Biol 8: 589, 2012.

16. Priebe A, Tan L, Wahl H, Kueck A, He G, Kwok R, Opipari A and Liu JR: Glucose deprivation activates AMPK and induces cell death through modulation of Akt in ovarian cancer cells. Gynecol Oncol 122: 389-395, 2011.

17. Chen Y, Qing W, Sun M, Lv L, Guo D and Jiang Y: Melatonin protects hepatocytes against bile acid-induced mitochondrial oxidative stress via the AMPK-SIRT3-SOD2 pathway. Free Radic Res 49: 1275-1284, 2015.

18. Wang SY, Wei YH, Shieh DB, Lin LL, Cheng SP, Wang PW and Chuang JH: 2-Deoxy-d-Glucose can complement doxorubicin and sorafenib to suppress the growth of papillary thyroid carcinoma cells. PLoS One 10: e0130959, 2015.

19. Wei L, Zhou Y, Dai Q, Qiao C, Zhao L, Hui H, Lu N and Guo QL: Oroxylin A induces dissociation of hexokinase II from the mitochondria and inhibits glycolysis by SIRT3-mediated deacetylation of cyclophilin D in breast carcinoma. Cell Death Dis 4: e601, 2013.

20. Jeong SM, Lee J, Finley LW, Schmidt PJ, Fleming MD and Haigis MC: SIRT3 regulates cellular iron metabolism and cancer growth by repressing iron regulatory protein 1 . Oncogene 34 : 2115-2124, 2015 .

21. Song J, Feng L, Zhong R, Xia Z, Zhang L, Cui L, Yan H, Jia X and Zhang Z: Icariside II inhibits the EMT of NSCLC cells in inflammatory microenvironment via down-regulation of Akt/NF- $\mathrm{B}$ signaling pathway. Mol Carcinog: Feb 9, 2016 (Epub ahead of print).

22. Liu Y, Veena CK, Morgan JB, Mohammed KA, Jekabsons MB, Nagle DG and Zhou YD: Methylalpinum isoflavone inhibits hypoxia-inducible factor-1 (HIF-1) activation by simultaneously targeting multiple pathways. J Biol Chem 284: 5859-5868, 2009.

23. Bonifati S, Daly MB, St Gelais C, Kim SH, Hollenbaugh JA, Shepard C, Kennedy EM, Kim DH, Schinazi RF, Kim B, et al: SAMHD1 controls cell cycle status, apoptosis and HIV-1 infection in monocytic THP-1 cells. Virology 495: 92-100, 2016.

24. Zhou X, Chen M, Zeng X, Yang J, Deng H, Yi L and Mi MT: Resveratrol regulates mitochondrial reactive oxygen species homeostasis through Sirt3 signaling pathway in human vascular endothelial cells. Cell Death Dis 5: e1576, 2014.

25. Zhang W, Tong D, Liu F, Li D, Li J, Cheng X and Wang Z: RPS7 inhibits colorectal cancer growth via decreasing HIF-1 $\alpha$ mediated glycolysis. Oncotarget 7: 5800-5814, 2016.

26. Yamada C, Aikawa T, Okuno E, Miyagawa K, Amano K, Takahata S, Kimata M, Okura M, Iida S and Kogo M: TGF- $\beta$ in jaw tumor fluids induces RANKL expression in stromal fibroblasts. Int J Oncol 49: 499-508, 2016.

27. Zhang M, Dong Y, Xu J, Xie Z, Wu Y, Song P, Guzman M, $\mathrm{Wu} \mathrm{J}$ and Zou MH: Thromboxane receptor activates the AMP-activated protein kinase in vascular smooth muscle cells via hydrogen peroxide. Circ Res 102: 328-337, 2008.

28. Hardie DG, Ross FA and Hawley SA: AMPK: A nutrient and energy sensor that maintains energy homeostasis. Nat Rev Mol Cell Biol 13: 251-262, 2012.

29. Luczak ED and Anderson ME: CaMKII oxidative activation and the pathogenesis of cardiac disease. J Mol Cell Cardiol 73: 112-116, 2014.

30. Dang CV: Links between metabolism and cancer. Genes Dev 26: 877-890, 2012.

31. Hensley CT, Wasti AT and DeBerardinis RJ: Glutamine and cancer: Cell biology, physiology, and clinical opportunities. J Clin Invest 123: 3678-3684, 2013.

32. Willems PH, Rossignol R, Dieteren CE, Murphy MP and Koopman WJ: Redox homeostasis and mitochondrial dynamics. Cell Metab 22: 207-218, 2015.

33. Murphy MP: How mitochondria produce reactive oxygen species. Biochem J 417: 1-13, 2009.

34. Pollak M: Overcoming drug development bottlenecks with repurposing: Repurposing biguanides to target energy metabolism for cancer treatment. Nat Med 20: 591-593, 2014. 
35. Birsoy K, Possemato R, Lorbeer FK, Bayraktar EC, Thiru P, Yucel B, Wang T, Chen WW, Clish CB and Sabatini DM: Metabolic determinants of cancer cell sensitivity to glucose limitation and biguanides. Nature 508: 108-112, 2014

36. Duarte FV, Amorim JA, Palmeira CM and Rolo AP: Regulation of mitochondrial function and its impact in metabolic stress. Curr Med Chem 22: 2468-2479, 2015.

37. Shackelford DB and Shaw RJ: The LKB1-AMPK pathway: Metabolism and growth control in tumour suppression. Nat Rev Cancer 9: 563-575, 2009.

38. Fennema E, Rivron N, Rouwkema J, van Blitterswijk C and de Boer J: Spheroid culture as a tool for creating 3D complex tissues. Trends Biotechnol 31: 108-115, 2013.

39. Lu PH, Chen MB, Ji C, Li WT, Wei MX and Wu MH: Aqueous Oldenlandia diffusa extracts inhibits colorectal cancer cells via activating AMP-activated protein kinase signalings. Oncotarget: Jun 13, 2016 (Epub ahead of print).

40. Inoki K, Zhu T and Guan KL: TSC2 mediates cellular energy response to control cell growth and survival. Cell 115: 577-590, 2003.

41. Wolff NC, Vega-Rubin-de-Celis S, Xie XJ, Castrillon DH, Kabbani W and Brugarolas J: Cell-type-dependent regulation of mTORC1 by REDD1 and the tumor suppressors TSC1/TSC 2 and LKB1 in response to hypoxia. Mol Cell Biol 31: 1870-1884, 2011.

42. Düvel K, Yecies JL, Menon S, Raman P, Lipovsky AI, Souza AL, Triantafellow E, Ma Q, Gorski R, Cleaver S, et al: Activation of a metabolic gene regulatory network downstream of mTOR complex 1. Mol Cell 39: 171-183, 2010.
43. Fanciulli M, Bruno T, Giovannelli A, Gentile FP, Di Padova M, Rubiu O and Floridi A: Energy metabolism of human LoVo colon carcinoma cells: Correlation to drug resistance and influence of lonidamine. Clin Cancer Res 6: 1590-1597, 2000.

44. Bentz S, Cee A, Endlicher E, Wojtal KA, Naami A, Pesch T, Lang S, Schubert P, Fried M, Weber A, et al: Hypoxia induces the expression of transketolase-like 1 in human colorectal cancer. Digestion 88: 182-192, 2013.

45. Qin Y,Cheng C,Lu H and Wang Y: miR-4458 suppresses glycolysis and lactate production by directly targeting hexokinase 2 in colon cancer cells. Biochem Biophys Res Commun 469: 37-43, 2016.

46. Fath MA, Diers AR, Aykin-Burns N, Simons AL, Hua L and Spitz DR: Mitochondrial electron transport chain blockers enhance 2-deoxy-D-glucose induced oxidative stress and cell killing in human colon carcinoma cells. Cancer Biol Ther 8: 1228-1236, 2009.

47. Raez LE, Papadopoulos K, Ricart AD, Chiorean EG, Dipaola RS, Stein MN, Rocha Lima CM, Schlesselman JJ, Tolba K, Langmuir VK, et al: A phase I dose-escalation trial of 2-deoxy-D-glucose alone or combined with docetaxel in patients with advanced solid tumors. Cancer Chemother Pharmacol 71: 523-530, 2013.

48. Ko YH, Verhoeven HA, Lee MJ, Corbin DJ, Vogl TJ and Pedersen PL: A translational study 'case report' on the small molecule 'energy blocker' 3-bromopyruvate (3BP) as a potent anticancer agent: From bench side to bedside. J Bioenerg Biomembr 44: 163-170, 2012. 